\title{
MORFOLOGI GISIK PANTAI DESA KALASEY SATU KECAMATAN PINELENG KABUPATEN MINAHASA
}

\section{(Morphology of Beach in Kalasey first Village at District of Pineleng Minahasa )}

\author{
Wilfrits F. F. Sasauw ${ }^{1 *}$, Hermanto W. K. Manengkey ${ }^{1}$, Esry T. Opa ${ }^{1}$ \\ ${ }^{1}$ Program Studi IImu Kelautan, Fakultas Perikanan dan IImu Kelautan, Universitas Sam \\ Ratulangi, Manado \\ *e-mail: wilfritssasauw@gmail.com
}

Human activities in coastal areas look very influential in the process of changing shoreline. Reclamation, population growth, and other human activities have an impact on changes in coastal areas, such as the occurrence of abrasion, waste disposal, coastal erosion, and sedimentation. Based on the initial survey, Kalasey Coast region suffered abrasion and result in partial loss of land due to the land in the form of waves and ocean currents. Based on the information society, the abrasion process has lasted about 30 years and is estimated to have occurred 500 meter shoreline setback. Results of research conducted in the period of the full moon, 08 - March 9, 2012 to get, beach beach Kalasey quite short and gentle slope criteria by riding Tidal water of $2.80 \mathrm{~cm}$, while the wave period of 2.25 to 8.97 seconds. Measured surface current, maximum 0.298 knots. Sediments are generally classified material ranging from fine sand to gravel. Granulometri sediment distribution curve shape is asymmetric beach robust to small size. The wedge has a very platykurtic criteria, platykurtic, leptokurtic, very leptokurtic, and mesokurtic. As preliminary information, the results of morphological studies beach Kalasey beach tourist area is likely to be tested for other time periods. It is hoped that efforts to manage this area is supported by the data and information beach style and its coastal areas are more adequate.

Keywords: beach morphological, cediment, Kalasey, coastal areas

Aktivitas manusia di wilayah pantai terlihat sangat berpengaruh pada proses perubahan garis pantai. Reklamasi, pertambahan penduduk, dan aktivitas manusia lainnya memberikan dampak terhadap perubahan wilayah pesisir, seperti terjadinya abrasi, pembuangan limbah, erosi pantai, dan sedimentasi. Berdasarkan survei awal, wilayah Pantai Kalasey mengalami abrasi dan mengakibatkan hilangnya sebagian lahan daratan yang disebabkan oleh proses laut berupa gelombang dan arus. Berdasarkan informasi masyarakat, proses abrasi telah berlangsung kurang 30 tahun dan diperkirakan telah terjadi kemunduran garis pantai 500 meter. Hasil penelitian yang dilakukan pada periode bulan purnama, 08 - 09 Maret 2012 didapatkan, gisik pantai kalasey tergolong kriteria lereng pendek dan landai dengan tunggang air pasut sebesar $2,80 \mathrm{~cm}$, sementara periode gelombang sebesar 2,25 - 8,97 detik. Arus permukaan terukur, maksimum 0,298 knot. Material sedimen umumnya tergolong mulai dari pasir halus hingga kerakal. Bentuk kurva distribusi granulometri sedimen gisik adalah asimetris kuat ke ukuran kecil. Peruncingan memiliki kriteria pada sangat platikurtik, platikurtik, leptokurtic, sangat leptokurtic, dan mesokurtik. Sebagai informasi awal, hasil studi morfologi gisik kawasan wisata Pantai Kalasey ini berpeluang diujikan untuk periode waktu lainnya. Dengan demikian diharapkan upaya pengelolaan daerah ini ditopang dengan data dan informasi corak gisik dan daerah pantainya yang lebih memadai.

Kata kunci: gisik, sedimen, Kalasey, area pesisir 


\section{PENDAHULUAN}

Daerah pantai merupakan suatu daerah pertemuan antara ekosistem daratan yang masih dipengaruhi prosesproses laut. Sunarto (1991) mendefinisikan batas wilayah pesisir mencakup wilayah darat sejauh masih dipengaruhi oleh proses dari laut, seperti pasang surut (pasut) dan rembesan air laut; serta wilayah laut sejauh masih mendapat pengaruh darat seperti aliran air tawar dan sedimentasi.

Pantai Kalasey memiliki berbagai potensi sumberdaya serta jasa lingkungan yang berpotensi untuk dimanfaatkan secara berkesinambungan, seperti pemukiman, pertanian, perkebunan, pariwisata, penambatan perahu dan sebagai penunjang akses transportasi antar wilayah. Dahuri $d k k$. (2001) menyatakan setiap perubahan bentang alam daratan dan dampak negatif lainnya seperti pencemaran, erosi, dan perubahan secara drastis regim aliran air tawar yang terjadi di ekosistem daratan (lahan atas) pada akhirnya dapat berdampak terhadap ekosistem pesisir.

Pengembangan pembangunan di sektor pariwisata terlihat begitu pesat di wilayah ini dengan berdirinya sejumlah bangunan pariwisata yang mendominasi wilayah pesisir Pantai Kalasey seperti diving center, cottage, resort, dan rumah makan. Perkembangan wilayah ini ditunjang dengan kebijakan daerah Kabupaten Minahasa yang tertuang dalam draft Rancangan Peraturan Daerah (RAPERDA) tentang Rencana Tata Ruang Wilayah (RTRW) 2011-2030 yang menetapkan kawasan Pantai Kalasey sebagai salah satu wilayah pengembangan wisata bahari dan pusat penyelaman (Anonimous 2011a).

Letak strategis Pantai Kalasey sebagai salah satu jalur utama penghubung wilayah Kota Manado dan sebagian wilayah bagian Barat Laut Kabupaten Minahasa, ternyata mampu menambah nilai ekonomis kawasan. Ruas jalan yang melintasi di sepanjang pesisir Pantai Kalasey dikategorikan

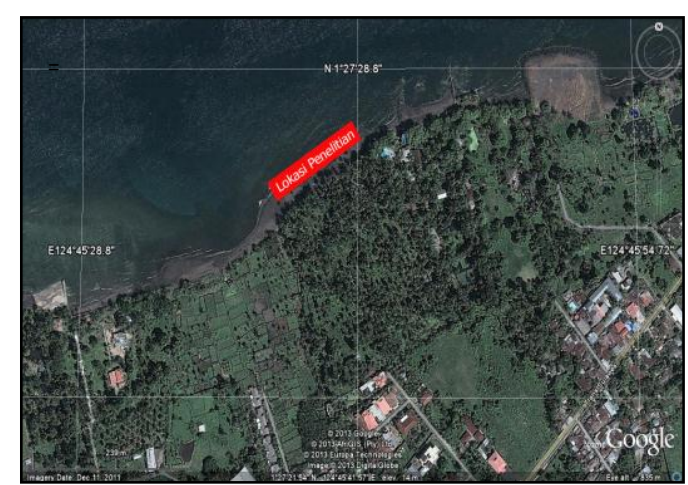

Gambar 1. Lokasi Penelitian

sebagai jalan arteri primer yaitu ruas jalan utama yang menghubungkan Pusat Kegiatan Nasional (PKN) dan Pusat Kegiatan Wilayah (PKW) (Anonimous 2011b).

Berdasarkan survei awal, wilayah Pantai Kalasey mengalami abrasi yang mengakibatkan hilangnya sebagian lahan daratan. Berdasarkan informasi yang diperoleh dari masyarakat, proses abrasi ini telah berlangsung lebih dari 30 tahun. Dalam rentang waktu tersebut diperkirakan telah terjadi kemunduran garis pantai hingga mencapai 500 meter.

$$
\text { Pethick (1997) menyatakan, }
$$
perkembangan gisik dapat dilihat dari dimensi butiran sedimen dengan kemiringan lereng yang selalu berubah akibat kuatnya gelombang. Jika gelombang kecil partikel sedimen yang terangkut berukuran kecil, jika gelombang besar dan kuat maka partikel sedimen yang terangkut berukuran besar. Penelitian morfologi gisik merupakan salah satu bagian dari ber-bagai rangkaian kegiatan untuk mendapatkan informasi aktual mengenai kondisi terkini kawasan Pantai Kalasey. Untuk itu keberadaan gisik di Pantai Kalasey perlu ditelaah, agar memungkinkan pengelolaannya secara optimal dan berkelanjutan.

\section{METODE PENELITIAN}

Contoh sedimen diambil dari tiga lokasi berbeda yang sebelumnya telah ditetapkan sebagai profil 1 dan 2 dan 3 . Masing-masing profil di-bagi atas tiga 
bagian, yakni atas, tengah, dan bawah. Se-banyak sembilan contoh sedimen mewakili ketiga profil dicuplik, selanjutnya ditangani di laboratorium dengan melakukan pencucian dan pengeringan. Setelah kering sedimen dipisahkan dengan ayakan yang masing-masing memiliki ukuran mata ayakan $0,05 \mathrm{~mm}$, $0,08 \mathrm{~mm}, 0,125 \mathrm{~mm}, 0,2 \mathrm{~mm}, 0,315 \mathrm{~mm}$, $0,5 \mathrm{~mm}, 0,8 \mathrm{~mm}, 1,25 \mathrm{~mm}, 2 \mathrm{~mm}, 3,15 \mathrm{~mm}$, $5 \mathrm{~mm}, 8 \mathrm{~mm}, 12,5 \mathrm{~mm}$, dan $20 \mathrm{~mm}$. Sedimen yang tertinggal di-masingmasing ayakan di-timbang dan hasilnya di-gambarkan pada grafik peubah distribusi granulometri.

Hasil penggambaran yang diperoleh digunakan untuk mengungkapkan ukuran pemusatan dan penyebaran partikel sedimen berupa rataan empirik $(\mathrm{Mz})$, pemilahan $\left(\delta_{1}\right)$, kemencengan $\left(S_{k}\right)$, dan peruncingan $(\mathrm{Kg})$, dengan melihat besaran-besaran distribusi granulometri sedimen pada grafik tersebut. Besaran yang dihasilkan dari grafik berupa $\varphi 5$, $\varphi 16, \varphi 25, \varphi 50, \varphi 75, \varphi 84$ dan $\varphi 95$ diolah berdasarkan model Folk dan Ward dalam Dyer (1986). Formula Pengolahannya adalah sebagai berikut:

\section{a. Rataan Empirik ( $\left.\mathbf{M}_{\mathbf{z}}\right)$}

$\mathbf{M}_{\mathbf{z}}=\left(\varphi_{16}+\varphi_{50}+\varphi_{84}\right) / 3$

b. Penyortiran ( $\sigma_{1}$, sigma satu)

$\sigma_{1}=\left(\varphi_{84}-\varphi_{16}\right) / 4+\left(\varphi_{95}-\varphi_{5}\right) / 6,6$

c. Kemencengan Kurva $\left(S_{k}\right)$

$S_{k}=\left[\left(\varphi_{16}+\varphi_{84}-2 \varphi_{50}\right) / 2\left(\varphi_{84}-\varphi_{16}\right)\right]$ $+\left[\left(\varphi_{5}+\varphi_{95}-2 \varphi_{50}\right) / 2\left(\varphi_{95}-\varphi_{5}\right)\right]$

d. Peruncingan Kurva (Kg)

$\mathbf{K g}=\left(\varphi_{95}-\varphi_{5}\right) / 2,44\left(\varphi_{75}-\varphi_{25}\right)$

Morfometri lahan diukur melalui penentuan kemiringan lereng gisik, dengan menggunakan peralatan profiler, yaitu dua tonggak papan dihubungkan dengan tali yang panjangnya $100 \mathrm{~cm}$ dan diberi busur derajat pada salah satu

tonggak tersebut. Pengukuran dilakukan dengan mendirikan kedua tonggak secara lurus pada permukaan lahan kemudian dilihat sudut yang dibentuk oleh tali dengan busur derajat. Sudut yang ter-bentuk menggambarkan perbedaan ke-tinggian pada permukaan lahan yang diamati.
Observasi pasut dilakukan secara sederhana menggunakan palem pasut yang ditempatkan dihadapan bangunan pelindung pantai ke arah laut yang dimanfaatkan untuk mengidentifikasi perubahan muka laut. Pengukuran periode gelombang ditentukan dengan bantuan stopwatch, yaitu dengan cara melihat selang waktu antara dua puncak gelombang berurutan melewati satu titik yang telah ditentukan. Untuk pengukuran arus dilakukan dengan menggunakan alat Floater Current Meter pada stasiun pengamatan yang telah ditentukan. Arah pergerakan pelampung dilihat dengan menggunakan kompas yang diidentifikasi sebagai arah pergerakan arus. Data yang diperoleh berupa jarak perpindahan atau jarak tempuh (s), kecepatan arus (V) dalam satuan knot dipehitungkan sebagai (S) dibagi (T) dan dikali 1,94 knot.

\section{HASIL DAN PEMBAHASAN}

Survei dilakukan pada tanggal 8-9 Maret 2012, menurut keadaan tunggang air pada saat periode bulan purnama. Dari hasil pengukuran didapatkan kemiringan lereng pada lahan gisik terkriteria landai ; dimana profil 1 terukur $4,6 \%$, profil 2 terukur $4,06 \%$ dan profil 3 terukur $5,91 \%$. Ketiga profil ini memiliki panjang lereng bervariasi yaitu $48 \mathrm{~m}$ untuk profil 1 dan $47 \mathrm{~m}$ untuk profil 2, dan $50 \mathrm{~m}$ untuk profil 3. Dalam Gambar 1 ditampilkan kemiringan lereng untuk kedua profil.

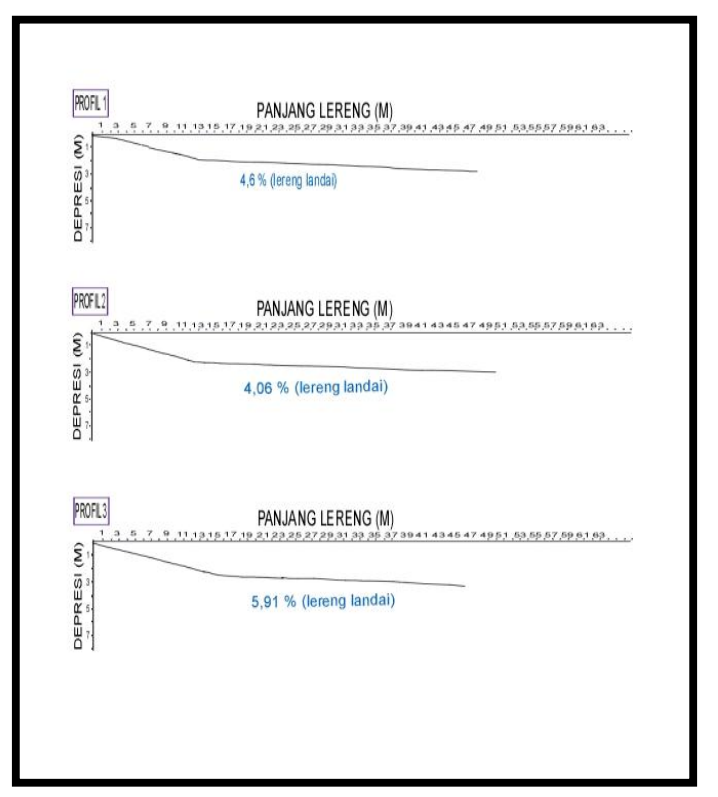

3 Gambar 2. Kemiringan lereng pada profil lahan gisik Pantai Kalasey. 


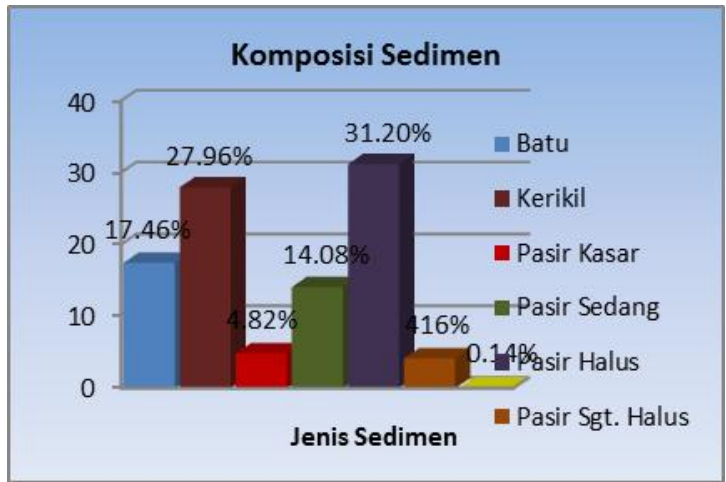

Gambar 3. Komposisi sedimen.

Komposisi sedimen di sekitar Pantai Kalasey ditemukan terbanyak $(31.20 \%)$ berupa pasir halus. Lebih rinci, persentase untuk masing-masing material lainnya, yakni kerikil $27.96 \%$, batu $17,46 \%$, pasir sedang $14,08 \%$, pasir kasar $4,82 \%$, kerikil $8 \%$, pasir sangat halus $4,16 \%$, dan debu $0,14 \%$ seperti ditampilkan pada Gambar 2 berikut.

Secara keseluruhan kisaran nilai rataan empirik sedimen yang diperoleh bervariasi mulai dari $-3,40-2,96$, terklasifikasi sebagai kerakal. Tabel 1 berikut ini merupakan ringkasan hasil analisis dan peubah-peubah distribusi granulometri.

Hasil cuplikan sedimen di sekitar Pantai Kalasey, profil 1 memiliki penyebaran sedimen mulai dari pasir kasar (PK), kerakal (Ke) dan pasir halus $(\mathrm{PH})$. Kemudian, profil 2 penyebaran sedimennya dimulai dari pasir sedang (PS), dan kerakal (Ke). Hal yang berbeda terjadi pada profil 3 dimana penyebaran sedimen tersusun mulai pasir sedang (PS), granul (Gra), dan kerakal (Ke).

\begin{tabular}{|c|c|c|}
\hline abel & $\begin{array}{l}\text { asil Peng } \\
\text { istribusi } \\
\text { edimen }\end{array}$ & $\begin{array}{l}\text { olahan Data } \\
\text { Granulometri }\end{array}$ \\
\hline $\begin{array}{l}\text { Peubah } \\
\text { Granulometri } \\
\text { Sedimen }\end{array}$ & Kisaran Nilai & $\begin{array}{l}\text { Lelas/Kriteria } \\
\text { Terbesar }\end{array}$ \\
\hline $\begin{array}{c}\text { Rataan Empirik } \\
(\mathrm{Mz})\end{array}$ & $-3,40-2,96$ & Kerakal \\
\hline Penyortiran $\left(\sigma_{1}\right)$ & $-1,23-3,04$ & Tersortir Buruk \\
\hline $\begin{array}{c}\text { Kemencengan } \\
\text { Kurva (Sk) }\end{array}$ & $-0,16-0,82$ & $\begin{array}{l}\text { Asimetris ke } \\
\text { Ukuran Kecil }\end{array}$ \\
\hline $\begin{array}{l}\text { Peruncingan } \\
\text { Kurva (Kg) }\end{array}$ & $0,26-2,39$ & Mesokurtik \\
\hline
\end{tabular}

Penyortiran granulometri sedimen pada gisik yang bervariasi tersusun dimulai dari tersortir sangat baik, tersortir baik, tersortir sedang, tersortir buruk, dan tersortir sangat buruk. Kisaran nilai kemencengan yang terbanyak tergolong pada kriteria simetris granulometri dan asimetris kuat ke ukuran kecil tersebar pada profil 2, dan 3 , sedangkan pada profil 1 memiliki nilai kemencengan yang lebih bervariasi yaitu kriteria simetris granulometri, asimetris kuat ke ukuran kecil. Distribusi granulometri yang terkriteria dalam peruncingan sedimen pada setiap profil gisik juga berbeda menurut posisi pencuplikan sampel. Peruncingan yang terkriteria pada mesokurtik, leptokurtik dan plaktikurtik adalah yang terbanyak ditemukan pada gisik yang ditelaah. Selain itu kriteria lain yang ditemukan adalah kriteria sangat platikurtik pada bagian bawah gisik profil 1.

Kisaran tunggang air pasut yang terukur pada periode bulan purnama (Maret 2012) menghasilkan ukuran yang beragam antara $230 \mathrm{~cm}$ (maksimum) pada pukul 16.00 (periode tanggal 9) hingga $20 \mathrm{~cm}$ (minimum) pada pukul 22.00 (periode tanggal 8). Kisaran tunggang air yang terukur pada periode umur bulan ini yaitu $230 \mathrm{~cm}$ dengan ratarata muka laut setinggi $116 \mathrm{~cm}$ seperti yang diperlihatkan pada gambar 3 .

Tipe pasang-surut yang teranalisis berdasarkan data pengukuran tiap satu jam selama 24 jam di perairan Pantai Kalasey, adalah pasang surut campuran condong ke harian ganda (Cchg).

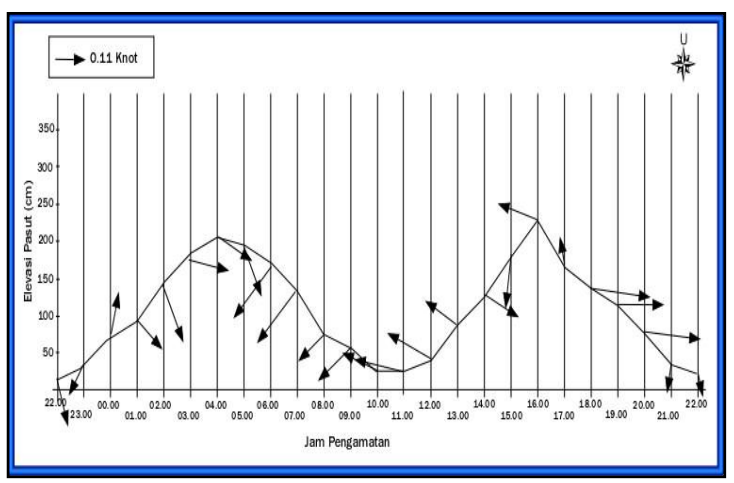

Gambar 4. Grafik Pasut dan Arah Arus di daerah survei. 
Arah arus terbanyak ke arah Baratdaya pada jam-jam tertentu dan nilai rata-rata arah arus selama dilakukan pengukuran adalah $189,920^{\circ}$. Selain Baratdaya arah arus lain yang bekerja pada lokasi penelitian ini adalah Utara, Timur, Timurlaut, Tenggara, Selatan, Barat, dan Baratlaut.

Periode gelombang terbesar (maksimum) adalah sebesar 8,97 detik dan terkecil (minimum) adalah 2,28 detik. Pengukuran dakian gelombang (run up) pada menghasilkan nilai yang bervariasi. Dakian gelombang tertinggi terukur dengan nilai 46 . Nilai dakian gelombang terendah adalah $10 \mathrm{~cm}$.

\section{KESIMPULAN}

Gisik di kawasan Pantai Kalasey yang telah ditelaah dapat disimpulkan morfologinya selama periode bulan purnama, 08 - 09 Maret 2012. Beberapa butir kesimpulan dikemukakan di bawah ini.

1. Gisik di kawasan wisata Pantai Kalasey memiliki kriteria lereng landai dengan nilai yg bervariasi dari profil 1 sampai 3 yaitu, 4,6\%, 4,06\%, 5,91\% . hal serupa juga terjadi pada panjang lereng yang bervariasi yaitu pada profil 1 memiliki panjang $48 \mathrm{~m}$, profil 2 memiliki panjang $50 \mathrm{~m}$, dan profil 3 memiliki panjang $47 \mathrm{~m}$.

2. Faktor hidro-oseanografi yang berkontribusi dalam dinamika gisik tersebut, ditandai oleh tunggang air pasang-surut sebesar $280 \mathrm{~cm}$ dan geraknya bersama rambatan gelombang berperiode 2,25-8,97 detik, arus permukaan yang terukur berkecepatan maksimum 0,298 knot orientasinya terbesar mengarah ke Timur.

3. Hamparan material sedimen umumnya tergolong pasir halus, pasir sedang, pasir kasar dan kerakal dengan rataan empirik dari distribusi granulometri sedimen yang dominan adalah Kerakal dan tersortir buruk. Kurva dari distribusi granulometri sedimen gisik ini umumnya diperlihatkan dalam bentuk asimetris kuat ke ukuran kecil dan simetris granulometri serta peruncingan yang terkriteria pada sangat platikurtik, platikurtik, leptokutik, sangat leptokurtik,dan mesokurtik sebagai kelas kriteria terbesar.

4. Sebagai informasi awal, hasil studi morfologi gisik kawasan wisata Pantai Kalasey ini berpeluang diujikan untuk periode waktu lainnya. Dengan demikian diharapkan upaya pengelolaan daerah ini ditopang dengan data dan informasi corak gisik dan daerah pantainya yang lebih memadai.

\section{DAFTAR PUSTAKA}

Anonimous, 2011a. Bantek Penyusunan Rencana Tata Ruang Wilayah Kabupaten Minahasa. Bab 4 Rencana Pola Ruang. Pdf 2011b. Draft Rancangan Peraturan Daerah Rencana Tata Ruang Wilayah Kabupaten Minahasa Tahun 2011-2030. Pdf

Dahuri, H.R., J. Rais, S.P. Ginting dan M.J. Sitepu, 2001. Pengelolaan Sumberdaya Wilayah Pesisir dan Lautan Secara Terpadu. PT. Pradnya paramita. Jakarta. 328 hal.

Dyer, K.D., 1986. Coastal and Estuarine Sediment Dynamics. John Wiley and Sons. Chichester. $342 \mathrm{p}$.

Pethick, J., 1997. An Introduction to Coastal Geomorphology. Edward Arnold Publ. Ltd. London. 259 hal.

Sunarto,1991. Geomorfologi Pantai. Pusat Antar Universitas IImu Teknik. Universitas Gadjah Mada. Yogyakarta. 52 hal. 